Acta Botanica Brasilica - 35(2): 290-297. April-June 2021.

\title{
Safe sex: ant defense does not interfere with pollination in passion flowers
}

\author{
Tiago Valadares Ferreira' (D), Thiago Junqueira $\mid z_{2} 0^{2}$ (1) and Alberto López Teixido ${ }^{2 *}$ (1)
}

Received: August 31, 2020

Accepted: December 25, 2020

\begin{abstract}
Ant defense against floral enemies incurs a two-fold ant-pollinator conflict, both via pollinator deterrence and nectar or pollen collection by non-pollinating protective ants. Some ant-plants have physical barriers whereas others produce ant-repellent chemicals to avoid ant visitation to flowers and subsequent pollination interference. Passiflora coccinea is a hummingbird-pollinated myrmecophilous plant in which floral enemy repellence occurs without limiting ant access to open flowers. To test the hypothesis that ant activity is restricted within flowers to prevent contact with anthers, we compared ant defense response between reproductive (anthers and stigmas) and non-reproductive (bracts, corona and perianth) floral structures by combining an observational survey with an experimental approach. A few insect species were found to visit flowers without providing pollination service, mostly pollen-collecting bees and nectar-thieving butterflies landing on petals. Ants always attacked floral visitors that landed on non-reproductive structures, but they never attacked insects visiting reproductive structures as ants never accessed anthers. Our results suggest that the differential ant defense response is an adaptative process to prevent ant-pollinator conflict. The eventual mechanism that regulates this process could be closely linked to the corona of filaments that protects nectar chambers, simultaneously restricting ant access to nectar and pollen.
\end{abstract}

Keywords: ant-pollinator conflict, ant protection, corona, extrafloral nectaries, extranuptial nectaries, floral enemies, flower reproductive structures, nectar thieves, Passiflora coccinea, pollination

\section{Introduction}

Animal-pollinated plants have to deal with a diverse assemblage of illegitimate floral visitors (e.g. florivores, nectar thieves) that consume substantial amounts of flower tissues, alter nectar availability and degrade pollinator attractiveness properties, which may ultimately reduce plant reproductive success (Galen 1999; McCall \& Irwin 2006; Irwin et al. 2010; Moreira et al. 2019). Consequently, plants have developed a set of defense mechanisms and strategies to avoid or, at least, minimize the damage produced by floral enemies. Although some of these defensive systems have generally evolved to deter herbivores of vegetative tissues, they are also commonly and efficiently used to protect reproductive organs, even produced only during the flowering period in some species (Agrawal 1998; Karban \& Baldwin 2007; Dutton et al. 2016). For example, indirect defense provides protection against herbivory and, in some cases, exclusively against florivory and nectar-thieving from flowers via mutualistic interaction with natural predators (Heil \& McKey 2003; Trager et al. 2010; Lortzing et al. 2016).

1 Programa de Pós-Graduação em Ecologia e Conservação da Biodiversidade, Universidade Federal de Mato Grosso, 78060-900, Cuiabá, MT, Brazil 2 Departamento de Botânica e Ecologia, Universidade Federal de Mato Grosso, 78060-900, Cuiabá, MT, Brazil

* Corresponding author: alberto.lopez.teixido@gmail.com 
Myrmecophily is a pervasive form of indirect defense against herbivores of vegetative and reproductive organs. Ant-plant mutualistic interactions are biogeographically widespread and present across a diverse range of plant taxonomic groups (Davidson et al. 1989; Heil \& McKey 2003; Rico-Gray \& Oliveira 2007; Trager et al. 2010). The production of nectar to attract plant defenders (i.e. unrelated to pollinators; Heil 2011) is the most prevalent mechanism of ant-mediated indirect defense in myrmecophytic plants (see Weber et al. 2015). Secretory structures that excrete patrolling-related nectar and other chemical compounds as feeding resource for ants are often extrafloral (extrafloral nectaries), but they can also be located within flowers (extranuptial nectaries, sensu Delpino 1886; see also Mesquito-Neto et al. 2020 and references therein). Ant protective action, however, can concomitantly involve several types of conflicts for plants in terms of pollination (i.e. ant-pollinator conflict: Willmer \& Stone 1997; Ness 2006; Assunção et al. 2014; Villamil et al. 2019). First, ants are mostly non-pollinating insects that may consume floral nectar and collect pollen without providing pollination services (Hölldobler \& Wilson 1990; Rico-Gray \& Oliveira 2007; Villamil et al. 2019). Second, ants may hinder pollination by repelling or directly attacking insect pollinators, thus ultimately reducing host plant's reproductive success (Willmer \& Stone 1997; Byk \& DelClaro 2010; Assunção et al. 2014; Ibarra-Isassi \& Oliveira 2018; Santos \& Leal 2019). In brief, myrmecophilous plants face a two-fold trade-off as ant-mediated protection against floral enemies raises two non-exclusive ant-pollinator conflicts.

From an evolutionary perspective, it is expected a defense strategy to be potentially selected when producing a positive net cost-benefit balance for plant fitness (i.e. optimal defense theory: Stamp 2003); that is, by reducing the antpollinator conflict without compromising defense against floral enemies. In this regard, a wide set of mechanisms have been related to avoidance of ant visitation to flowers and pollinator deterrence during anthesis. For example, some species have physical barriers as pedicels or spines on corollas, calyces or floral pedicels that prevent ant movement (e.g. Stephanotis; reviewed in Willmer 2011). Other myrmecophilous plants produce different antrepellent floral volatile compounds, mostly during the anthesis, to reduce ant access to flowers only when are open and functional (Willmer \& Stone 1997; Raine et al. 2002; Junker et al. 2007; Ballantyne \& Willmer 2012). Still, in some myrmecophilous species ant protection against floral enemies improves plant reproductive success without limiting ant access to open flowers. Pollination by large-sized pollinators (e.g. vertebrates) that are hardly influenced by patrolling ants could potentially account for this process. For example, Passiflora coccinea is a hummingbird-pollinated Neotropical myrmecophilous plant (Fig. 1) in which ant protection against floral nectar thieves does not interfere with pollinators and significantly increases seed production in ant-visited flowers when compared to ant-removed flowers (Leal et al. 2006). However, flowers of $P$. coccinea are also visited by pollen-collecting bees that do not contact stigmas (Storti 2002), but nothing is known about the ant protective role against these floral visitors and whether flower-visiting ants access anthers. Therefore, further research is required to unravel the ant intrafloral activity and its interference with the ant-pollinator conflict in systems wherein ants access flowers.

Here, we combine an observational approach with experimental manipulation of insect visits on reproductive (anthers and stigmas) and non-reproductive (bracts, corona and perianth -petals and sepals-) structures of P. coccinea flowers to determine whether non-pollinating protective ants access anthers and show a selective defense response among visitors on the different floral structures. Specifically, we expect ants (1) to never access reproductive structures despite some pollen-collecting bees visiting anthers without providing pollination service and, consequently, (2) to exclusively protect flowers against potential nectar-thieving visitors landing on non-reproductive structures. Evidence in this sense would potentially explain a reduced ant-pollinator conflict in flower-visiting ant-mediated protection against floral enemies.

\section{Materials and methods}

\section{Species and study site}

The study was conducted in August 2019 along a 2-km transect at the edges $(0-20 \mathrm{~m}$ towards forest interior) of a 7,000-ha natural fragment of a tropical moist broadleaf forest of southern Amazonia adjacent to pasture areas for cattle located at Fazenda São Nicolau, Cotriguaçu, Mato Grosso, Brazil (951'21” S - 58¹4'52”' W; Fig. S1 in supplementary material). The area is characterized by different land uses resulting of human perturbation, wherein pasture lands and reforestation areas are interspersed with secondary forest patches bordered by larger areas of primary forest (Rodrigues et al. 2011). The climate in this area is classified as Aw, hot and wet, according to the Köppen's system, with mean annual temperature of $24^{\circ} \mathrm{C}$ and precipitation of 2,300 $\mathrm{mm}$ (Rodrigues et al. 2011).

Passiflora coccinea Aubl. (Passifloraceae) is a Neotropical and evergreen woody vine inhabiting disturbed areas of humid forests and savannas from Central America to southern Amazon (Pio-Corrêa 1978; Ribeiro et al. 1999; Fischer \& Leal 2006). Flowering spans between July and February, and blooming individuals open a few hermaphroditic, nectariferous and red disc-shaped individual flowers daily, about $7-12 \mathrm{~cm}$ in diameter, with three external bracts, five sepals, five petals in an alternate arrangement with sepals, five anthers and a superior ovary 
with three stigmas raised on an androgynophore surrounded by a corona with multiple filaments (Storti 2002; Fig. 1A-B). $P$. coccinea produces a few extrafloral nectaries on the leaf blade and a set of extranuptial nectaries located on the border of floral bracts, which are visited by more than 20 ant species, mostly of the genera Camponotus, Crematogaster, Ectatomma and Pseudomyrmex (Wirth \& Leal 2001; Leal et al. 2006). Flowers open in the predawn and last fully open and functionally active during a few hours, closing before midday (Storti 2002; Fischer \& Leal 2006). The hummingbird species Phaethornis superciliosus pollinates flowers when collecting nuptial nectar (Fig. 1C), located in chambers protected by the corona, contacting its head with the reproductive structures (Storti 2002; Fischer \& Leal 2006). A few insects also visit flowers, mostly a few pollen-collecting bees and nectar-thieving butterflies that do not provide pollination service (Storti 2002; Fig. 1D-F). $P$. coccinea is a xenogamous and self-incompatible species, dependent on hummingbird-mediated cross-pollination for seed production (Storti 2002).

\section{Data collection}

Along six consecutive days in the morning (between 7:00 and 11:00) we observed floral visitors (i.e. pollinators, pollen-collecting bees and nectar thieves) and ant defense response on 52 flowers of 18 flowering individuals.
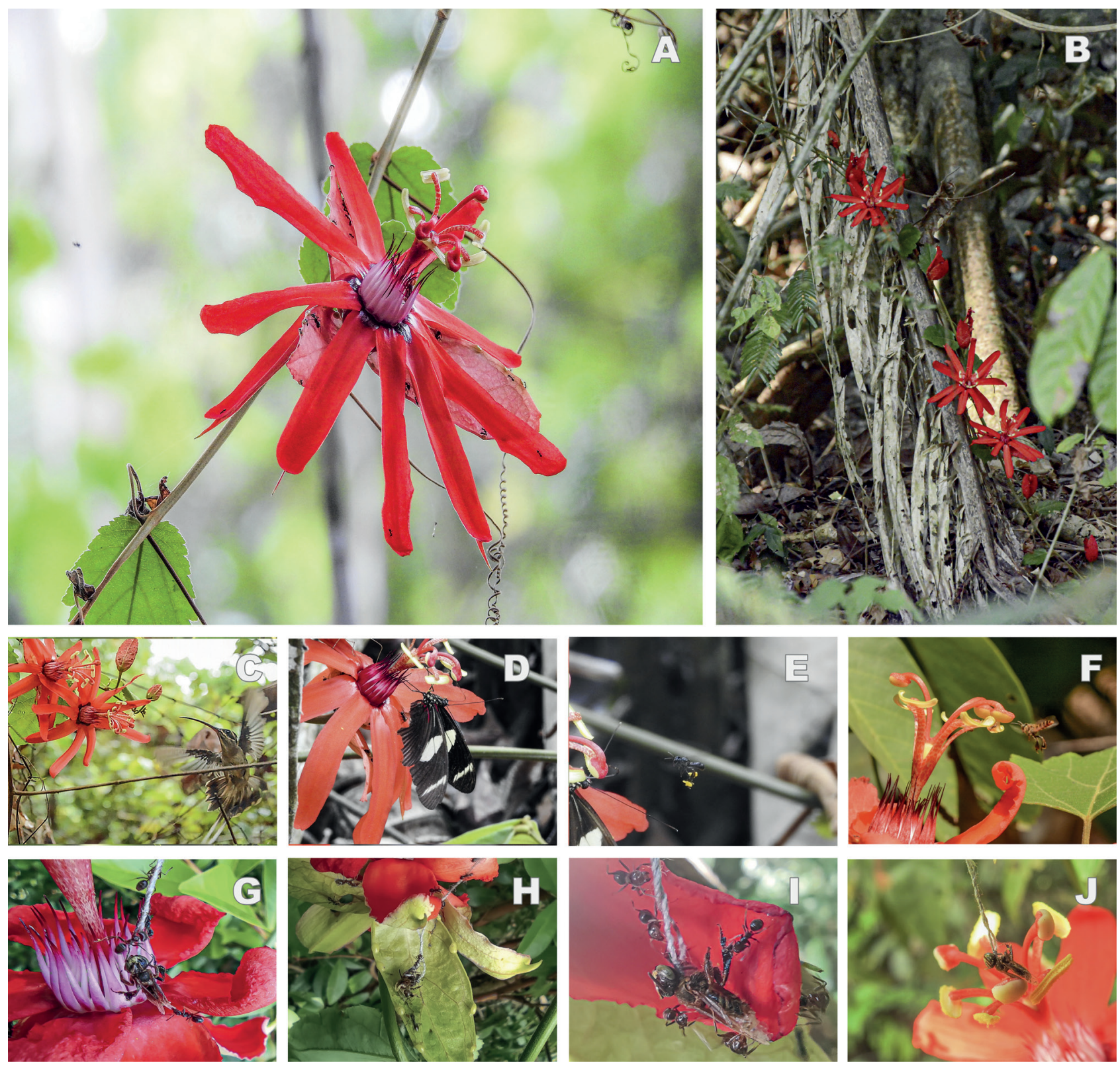

Figure 1. Flowers and individuals of Passiflora coccinea used in the study (A, B), with detailed images of some floral visitors (C - Phaethornis superciliosus; D - a nectar-thieving butterfly; E, F - pollen-collecting bees) and ant attack on bees used during the experiment on the different floral structures ( $\mathbf{G}$ - corona; $\mathbf{H}$ - bracts; I - perianth; $\mathbf{H}$ - reproductive structures). 
The ants present on each individual were collected and their identification matched the ants found in other studies conducted in the same area (e.g. Dáttilo et al. 2014; Vicente \& Izzo 2017). However, we did not record which ant genera are more aggressive or account for most of attacks. Here, we explicitly focused on the ant defense response between nonreproductive and reproductive floral structures, regardless of specific defense response across different ant genera.

The observations of floral visitors were conducted by ourselves by means of either direct observations or digital video recording using 2 second time-lapse sequence photography (Nikon D7100, AF-P 70-300mm F/4.5-6.3G, Nikon Group, Japan). Direct observations were conducted during 10-min periods between 7:00 and 9:00 at a distance of ca. $1 \mathrm{~m}$ from the focal flower to give a total of five or six observation continuous periods per day and 34 periods, totaling $340 \mathrm{~min}$ (ca. $6 \mathrm{~h}$ ). Observations with video camera followed the same protocol as direct observations, giving a total of three observation periods per day between 9:00 and 11:00 (18 periods, totaling $180 \mathrm{~min} ; 3 \mathrm{~h}$ ). During each observation period we noted the number and taxonomic group of floral visitors (species were not identified, but Phaethornis superciliosus) and floral structure visited (i.e. bract, corona, perianth -petals and sepals-, and reproductive structures -anthers and stigmas-). Since we focused on ant defense response, a visit was exclusively recorded when a floral visitor landed on any of floral structures. Thus, hummingbird's tongue- or bill-mediated contacts on the reproductive organs recorded were not ultimately considered in our analysis, as hummingbirds hover during their visits and are not influenced by patrolling ants (Leal et al. 2006). As flowers of $P$. coccinea are large and each of floral structures clearly conspicuous, it was easily possible to distinguish visits contacting each of these parts. For each visit, we also recorded whether ants attacked or not, considering attack as any physical interaction between ants and floral visitors. We considered physical interaction instead of merely recording defense-related ant behaviour changes or movements because of four reasons: (1) some visits were only sporadic, (2) ant movements on the flowers are dynamic and hardly related to aggressive behaviour, (3) all observed ant species were known as aggressive against herbivores in other systems, and (4) to avoid false positives.

However, this procedure could instead lead to false negatives, as some floral visitors may leave the flower before any physical interaction with ants, especially visits on reproductive structures. To avoid this limitation, we conducted an experiment in addition to the natural observation of floral visitors and ant response by simulating floral visits on the different floral structures. To do this, we used recently dead bee individuals (species was not identified) from a species visiting $P$. coccinea flowers previously collected and kept in small lab sterile bottles. The bees were carefully located on the different floral structures of six flowers from six different individuals ( $\mathrm{n}$
$=24$ observations) for at most five minutes to determine the ant attack and removed after this occurred (i.e. the first physical ant-bee interaction occurred; Fig. 1G-J). Any potential influence of using dead bees instead of living ones on ant attack was similar in the different floral structures. Besides recording the presence or not of ant attack, we quantified the time elapsed since we located the dead bee on a given floral structure and ant-bee physical interaction.

\section{Data analysis}

To test for significant differences in the ant attack (i.e. ant-visitor physical interaction) between floral visitors and structures in our observational approach, we fitted a Generalized Linear Mixed Model (GLMM). We included floral visitor and floral structure as fixed factors in the model. We also considered the variation within plants by adding this variable as a random factor in our model. Thus, we included a statistical control of this source of variation. A full model should also include the interaction floral visitor $\times$ floral structure, wherein a significant interaction indicates a differential effect of the floral structure on ant defense response depending on the floral visitor. However, the low number of samples ( $\mathrm{n}=55$ floral visits) and the number of interactions ( $n=12$; 3 floral visitors $\times 4$ floral structures; see Results) did not let us get a deviance, a reliable test value or a $p$-value for the interaction. Either way, both the model we ran and the full model showed ultimately the same results for floral visitors and floral structures. We considered a binomial (presence or absence of ant defense response) error distribution using the MASS package (Venables \& Ripley 2013) in R software (R Development Core Team 2018). The model was analyzed using the restricted maximum likelihood (REML). We also performed post-hoc pairwise comparisons to determine significant differences in ant defense response among floral structures using the lsmeans package (Lenth 2016).

For the experimental design we did not conduct any analysis since the results were totally contrasting between reproductive organs and the other floral structures ( 0 vs $100 \%$ of presence in ant defense response, respectively; see Results). Instead, we tested for significant differences in the time elapsed in the ant defense response between non-reproductive floral structures (bracts, corona and perianth) by fitting a Generalized Linear Model (GLM). We considered a Poisson error distribution and performed post-hoc pairwise comparisons to determine significant differences in time elapsed in the ant defense response among floral structures as explained above.

\section{Results}

We recorded four taxonomic groups of floral visitors (bees -Hymenoptera-, bugs -Hemiptera-, butterflies Lepidoptera- and hummingbirds) comprising 64 visits to 


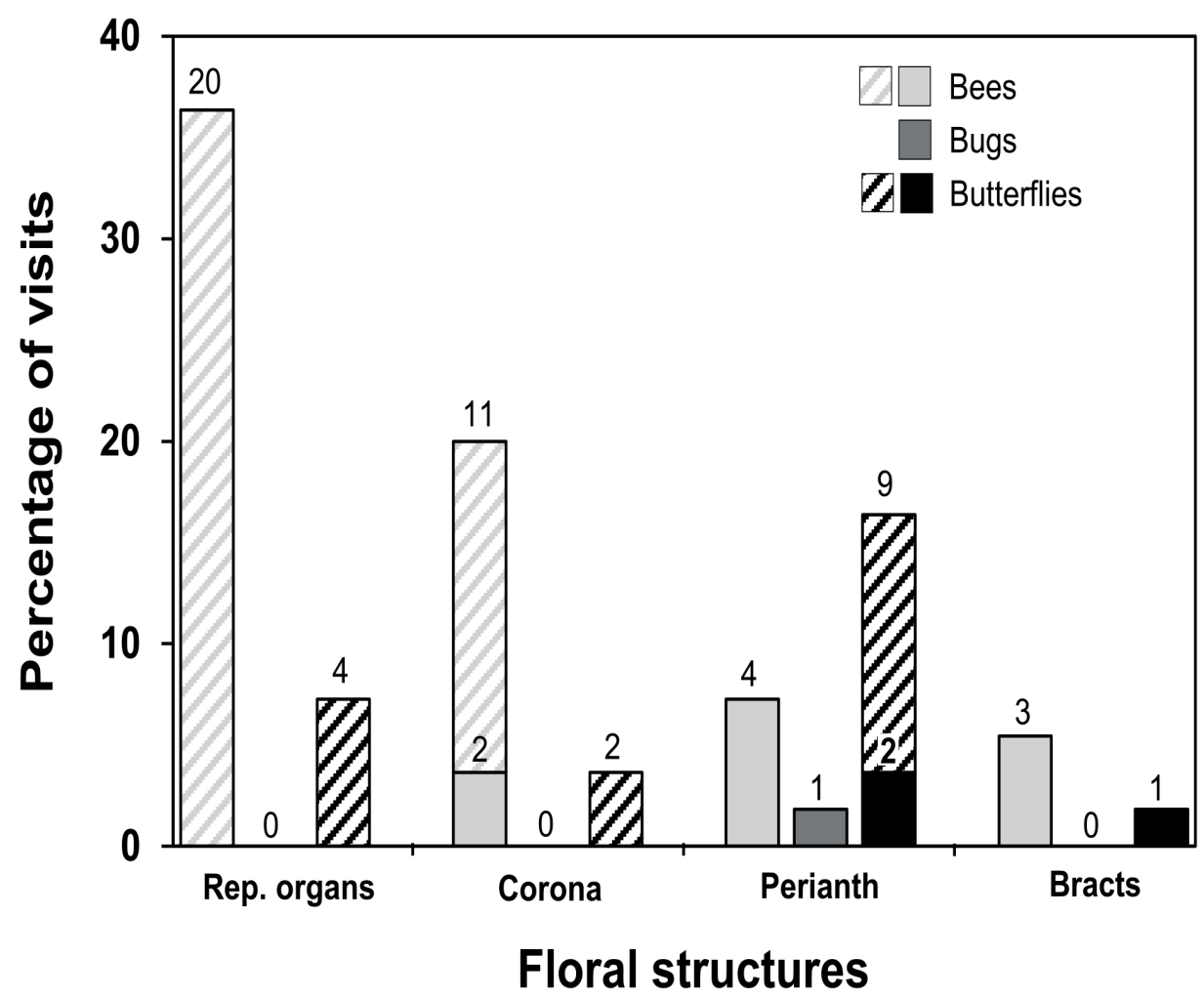

Figure 2. Percentage of visits carried out by the different floral visitors (excluding hummingbirds, see Materials and methods) on each of floral structures of Passiflora coccinea flowers. Solid bars show visits attacked by ants whereas hatched bars show non-attacked visits. Total number of visits are represented on each bar.

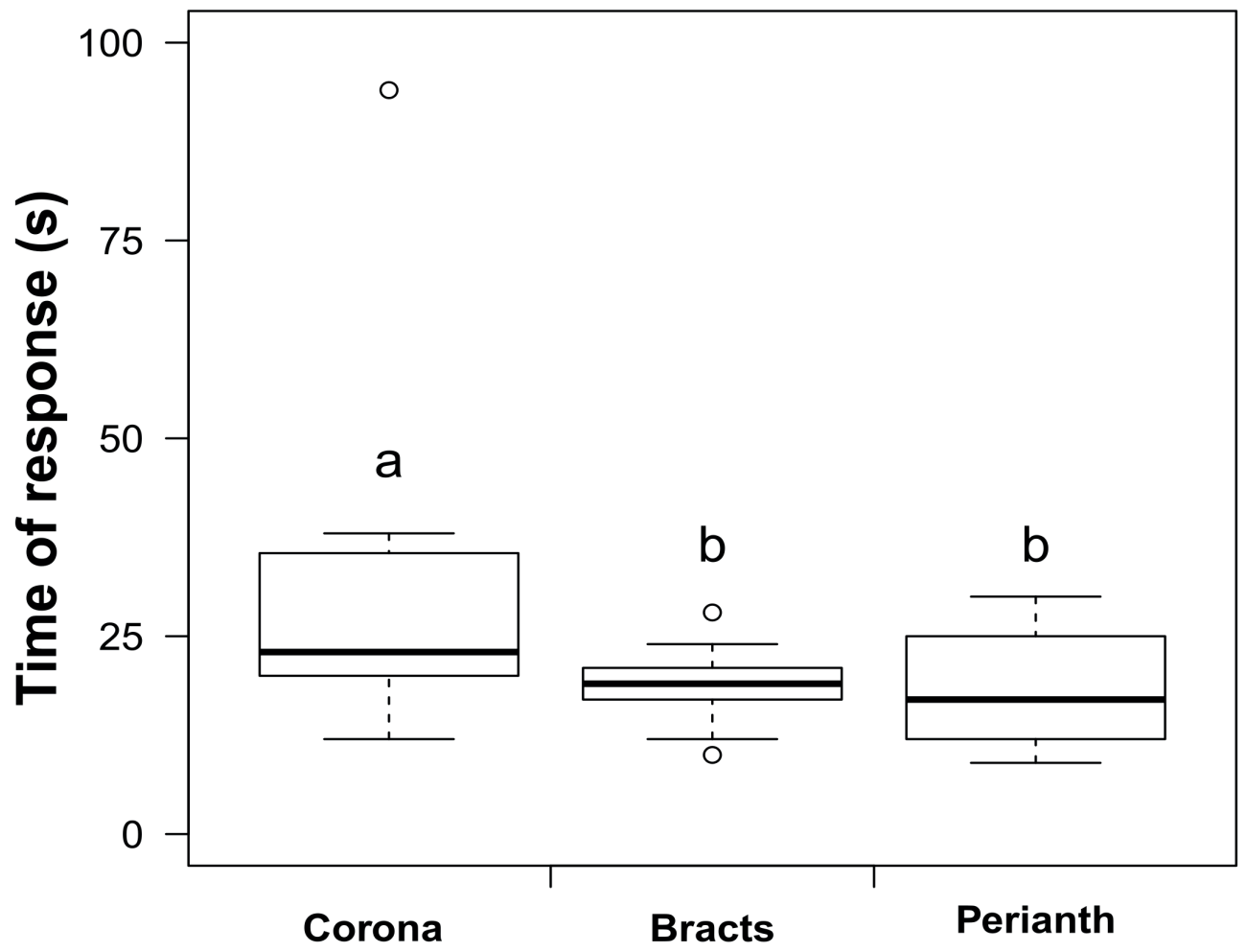

Figure 3. Box-plots showing medians and quartiles of time elapsed for the first ant attack, measured as the time the first physical contact between ant and bee occurred, across floral structures of Passiflora coccinea flowers. Different letters show significant differences $(P<0.05)$. 
flowers of $P$. coccinea. However, we excluded hummingbird visits (nine visits) and exclusively focused on floral visitors landing on flowers as explained above (see Materials and methods). Thus, pollen-collecting bees (69\% of visits) and nectar-thieving butterflies ( $29 \%)$ species were the most frequent visitors, whereas bugs only comprised one visit (Fig. 2). Reproductive organs were the most visited floral structure ( $44 \%$ of visits), followed by the perianth ( $25 \%)$, the corona (24\%), and bracts (7\%). Bees were the most recurrent visitors on reproductive organs, butterflies usually landed on petals and occasionally contacted reproductive organs, whereas the only visit reported by bugs was on sepals.

We recorded four ant species in flowers of $P$. coccinea: Camponotus femoratus, Crematogaster levior, Azteca chartiflex and Pheidole gertrudae. In our study observational, we noted thirteen attacks to floral visitors (ca. $20 \%$ of visits). However, ant attack significantly differed between floral visitors $\left(\chi^{2}=\right.$ $12.36, P=0.004)$ and structures $\left(\chi^{2}=39.16, P<0.001\right)$. Most interestingly, floral visitors contacting the reproductive organs did not suffer any attack and only $10.5 \%$ of the visits to the corona were defended (Fig. 2). Otherwise, all visits to bracts and $50 \%$ to perianth entailed ant attack (Fig. 2). We found significant differences in ant defense response between bracts and perianth $(P<0.001)$ and between these structures and reproductive organs or corona $(P<0.01$ for all pairwise comparisons). Our experiment reinforced the differences in ant defense response between reproductive and non-reproductive structures. For all experimental replicates, the reproductive organs were never defended as ants show a consistent behavior and did not ever access these structures, whereas bracts, corona and perianth always were. Mean time that ant attack took to appear, measured as the time the first physical interaction between ant and bee occurred, was significantly about two-fold longer in the corona than in bracts and perianth, which did not show any difference in time of attack (Fig. 3).

\section{Discussion}

By combining an observational survey with an experimental approach, our study shows compelling novel evidence that floral visitors that land on flower reproductive organs of $P$. coccinea are never attacked by ants, as they do not ever access these structures. Thus, differential ant defense response among floral structures with no access of ants to pollen is a relevant process across the diverse and widespread interaction between ants and plants. In this context, the ant's inability to attack floral visitors on anthers and stigmas may be regarded as an important adaptative mechanism in P. coccinea to ameliorate potential conflicts to pollination of flower-visiting non-pollinating ants without altering the defense against potential floral enemies visiting non-reproductive structures that do not provide pollination services.
Previous studies have shown that ants seldomly access flowers across extrafloral nectary-bearing plants (see Villamil et al. 2019 and references therein), whereas differential ant attack among floral structures has so far been overlooked. In $P$. coccinea, this activity may fairly be related to the specialized hummingbird-mediated pollination system. While foraging flowers, individuals of Phaethornis superciliosus hover to collect nectar and are not chased away by ant presence (Fischer \& Leal 2006). Therefore, ant access to flowers does not involve indirect ecological costs in terms of pollinator deterrence, overcoming one of the main ant-pollinator conflicts. Ant activity within flowers entails a benefit by averting nectar-thieving butterflies to land on the corolla or, accordingly to our results, chasing them away once on the petals (Leal et al. 2006). In contrast, we also observed some pollen-collecting bees foraging on anthers that were not attacked by ants. However, an important caveat of our study is that we lack data regarding differential bee visitation rates between ant-visited and ant-removed flowers. In this regard, ant presence in flowers could still deter some bees and reduce their visitation rates and/or duration (LeVan \& Holway 2015; Ibarra-Isassi \& Oliveira 2018). Likewise, it would be interesting to determine whether this pollen theft can ultimately compromise the male fitness by reducing siring success. Although pollen is usually overproduced across animal-pollinated plants and male function is limited by the number of mating events (Burd \& Callahan 2000; Teixido et al. 2016), native pollen thieves can still reduce male pollination components (Hargreaves et al. 2010). Other stimulating topic would be to disentangle the ant defense response against hemipteran species, which may be more abundant in our study system. Although most hemipterans are herbivores (e.g. stink bugs, Pentatomidae), some species prey upon pollinators (e.g. assassin bugs, Reduviidae), disrupting plant-pollinator mutualisms (Benoit $\&$ Kalisz 2020). Hence, ant attack against these predators could entail an additional benefit to plants beyond defense against herbivores. Either way, our results suggest that ant interaction in $P$. coccinea maximizes protection against nectar thieves without incurring the potential negative impacts of non-pollinating ant access to pollen.

The most plausible explanation for the eventual process that regulates the selective ant defense response among floral structures may be related to the corona of filaments of flowers. Flower nuptial nectaries in Passiflora species are in chambers protected by this floral structure (Durkee et al. 1981; see also Storti 2002 for P. coccinea). This protection could limit the access to nectar-thieving insects although, as described, some butterflies still consume nectar of $P$. coccinea flowers with their mouthparts by landing on perianth (see also Leal et al. 2006). Otherwise, the corona in flowers of $P$. coccinea seems rather to be a structure that acts as a physical barrier to simultaneously protect the accession of ants to nectar and anthers. Physical barriers such as floral pedicels and spiny or hairy corolla surfaces have been broadly related 
to reduction in ant visitation to flowers during anthesis by hampering their walking (Harley 1991; Willmer 2011). We suggest that the corona restricts ant access to nectar and pollen and, subsequently, pollination interference, but also ant protection against pollen-collecting bees and other illegitimate visitors on reproductive structures of $P$. coccinea flowers, but corona-removing experiments are required to take solid conclusions.

Together with the corona role, the emission of floral volatile compounds could disentangle the differential ant protection among floral structures to some extent. Mounting evidence reveals that ant-deterrent chemical signals in floral tissues are relatively common in myrmecophytic plants (e.g. Guerrant \& Fiedler 1981; Willmer \& Stone 1997; Ness 2006; Agarwal \& Rastogi 2008; Ballantyne \& Willmer 2012). In Vachellia (formerly Acacia) flowers, the repellent effect can even occur as a response to floral volatiles from pollen, averting ants just temporarily while flowers remain open and functional (Willmer et al. 2009). It is broadly known that some passion flowers produce nectar with volatile compounds related to pollinator attractiveness such as butterflies, bats and hummingbirds (Durkee et al. 1981; Varassin et al. 2001; DellaCuna et al. 2018; see also Fischer \& Leal 2006 for P. coccinea). Interestingly, Konstantinidis et al. (2010) found that flowers of Passiflora incarnata produce chemicals in tissues, but not in floral nectar, that can effectively repel ants. Following these assumptions, a similar process to pollen chemical-mediated ant deterrence reported among flowers at contrasting phenophases of Acacia species (Willmer et al. 2009) could take place among reproductive and non-reproductive floral structures within flowers of $P$. coccinea.

Lastly, the lack of ant aggressive behaviour on insects contacting anthers and stigmas may instead be related to larger spatial separation between reproductive parts and extranuptial nectaries, which could potentially reduce the chances of nectar-thieving from the latter structure. In this regard, an inherent indirect cost to the production of nectaries associated to ant-guarding is an increase in the frequency of nectar thieves foraging these nectaries (Aguirre-Jaimes et al. 2018). However, an exclusive ant patrolling of extrafloral or extranuptial nectaries in plants with floral nectar appears to serve more as a diversion of non-pollinating ants from visiting flowers rather than a protective role against floral enemies (i.e. distracting hypothesis: see Villamil et al. 2019 and references therein). In agreement to our results, the secretion of extranuptial nectaries and the ensuing interaction with ants in P. coccinea has been differently suggested as a defensive function for flowers against nectar thieves, which significantly increases seed production in individual plants (Leal et al. 2006). Therefore, the presence of ants in P. coccinea not only protects flowers against potential floral enemies but also does not interfere with potential pollinators.
Ants of the genus Pheidole and, especially, Camponotus and Crematogaster have been previously reported to be frequent and abundant in P. coccinea (Wirth \& Leal 2001; Leal et al. 2006). All these genera are associated to extrafloral/ extranuptial nectaries and show adaptations to a liquid diet and to occupancy and foraging on the vegetation strata (Dáttilo et al. 2014). The four ant species identified in our study also show an extremely natural aggressive behavior by defending the area close to the food source (Dáttilo et al. 2014; Vicente \& Izzo 2017). Overall, these assumptions suggest that the ant species reported in our study are defenders equally efficient against floral enemies of $P$. coccinea.

In conclusion, our results reinforce the assumption that the production of extranuptial nectaries in P. coccinea is associated to ant-mediated indirect defense to protect flowers against potential nectar-thieving caused by illegitimate floral visitors. More interestingly, our study demonstrates that the visits of insects on reproductive organs are not defended by extranuptial nectary-associated patrolling ants, as they did not ever access these structures. As a consequence, ants do not access pollen, thus avoiding potential interferences with pollination. This inability in ant defense response may consequently be an adaptative process to prevent an ant-pollinator conflict in this species. The eventual mechanism that regulates this process seems to be closely linked to the corona of filaments that protects nectar chambers in P. coccinea flowers and congeneric species. The role of the production of chemicals in floral tissues (e.g. ant-repellent pollen) raises interesting open questions that deserve further attention.

\section{Acknowledgements}

We thank two anonymous reviewers for the suggestions provided during earlier versions of the manuscript. The Fazenda São Nicolau, MT, Brazil made the area available to conduct this study. We also thank EAS Paiva for providing suggestions in the earlier versions of the manuscript and KPCS Thomas for assisting with map elaboration. CAPES granted a MSc Scholarship to TVF. TJI is supported by CNPq (309552/2018-4).

\section{References}

Agarwal VM, Rastogi N. 2008. Deterrent effect of a guild of extrafloral nectary-visiting ant species on Raphidopalpa foveicollis, a major insect pest of sponge gourd, Luffa cylindrica. Entomologia Experimentalis Et Applicata 128: 303-311.

Agrawal AA. 1998. Induced responses to herbivory and increased plant performance. Science 279: 1201-1202.

Aguirre-Jaimes A, Dáttilo W, et al. 2018. Foraging ants on the extrafloral nectaries repel nectar thieves but not the effective pollinator of Vigna luteola (Fabaceae) in a Mexican coastal sand dune. Sociobiology 65: 621-629.

Assunção MA, Torezan-Silingardi HM, Del-Claro K. 2014. Do ant visitors to extrafloral nectaries of plants repel pollinators and cause an indirect cost of mutualism? Flora 209: 244-249. 
Ballantyne G, Willmer P. 2012. Nectar theft and floral ant-repellence: a link between nectar volume and ant-repellent traits? PLOS ONE 7: e43869. doi: 10.1371/journal.pone.0043869

Benoit AD, Kalisz S. 2020. Predator effects on plant-pollinator interactions, plant reproduction, mating systems, and evolution. Annual Review of Ecology, Evolution, and Systematics 51: 319-340.

Burd M, Callahan HS. 2000. What does the male function hypothesis claim? Journal of Evolutionary Biology 13: 735-742.

Byk J, Del-Claro K. 2010. Nectar- and pollen-gathering Cephalotes ants provide no protection against herbivory: a new manipulative experiment to test ant protective capabilities. Acta Ethologica 13: 33-38.

Dáttilo W, Marquitti FMD, Guimarães Jr PR, Izzo TJ. 2014. The structure of ant-plant ecological networks: is abundance enough? Ecology 95: 475-485.

Davidson DW, Roy R. 1989. Competition among ants for myrmecophytes and the significance of plant trichomes. Biotropica 21: 64-73.

Della-Cuna FSR, Calevo J, Giovannini A, Boselli C, Tava A. 2018. Characterization of the essential oil of the bat-pollinated Passiflora mucronata. Natural Product Communications 13: 1934578X1801301236. doi: 10.1177/1934578X1801301236

Delpino F. 1886. Funzione mirmecofila nel Regno vegetale. Memorie della Reale Accademia delle Scienze dell'Istituto di Bologna 7: 215-323.

Durkee LT, Gaal DJ, Reisner WH. 1981. The floral and extra-floral nectaries of Passiflora. I. The floral nectary. American Journal of Botany 68: 453-462.

Dutton EM, Luo EY, Cembrowski AR, et al. 2016. Three's a crowd: tradeoffs between attracting pollinators and ant bodyguards with nectar rewards in Turnera. The American Naturalist 188: 38-51.

Fischer E, Leal IR. 2006. Effect of nectar secretion rate on pollination success of Passiflora coccinea (Passifloraceae) in the Central Amazon. Brazilian Journal of Biology 66: 747-754.

Galen C. 1999. Why do flowers vary? The functional ecology of variation in flower size and form within natural plant populations. Bioscience 49: 631-640.

Guerrant Jr EO, Fiedler PL. 1981. Flower defenses against nectar-pilferage by ants. Biotropica 13: 25-33.

Hargreaves AL, Harder LD, Johnson SD. 2010. Native pollen thieves reduce the reproductive success of a hermaphroditic plant, Aloe maculata. Ecology 91: 1693-1703.

Harley R. 1991. The greasy pole syndrome. In: Huxley CR, Cutler DF. (eds.) Ant-plant interactions. Oxford, Oxford University Press. p. 430-433.

Heil M, McKey D. 2003. Protective ant-plant interactions as model systems in ecological and evolutionary research. Annual Review of Ecology, Evolution, and Systematics 34: 425-553.

Heil M. 2011. Nectar: generation, regulation and ecological functions. Trends in Plant Science 16: 191-200.

Hölldobler B, Wilson EO. 1990. The ants. Harvard, Harvard University Press.

Ibarra-Isassi J, Oliveira PS. 2018. Indirect effects of mutualism: anttreehopper associations deter pollinators and reduce reproduction in a tropical shrub. Oecologia 186: 691-701.

Irwin RE, Bronstein JL, Manson JS, Richardson L. 2010. Nectar robbing: ecological and evolutionary perspectives. Annual Review of Ecology, Evolution, and Systematics 41: 271-292.

Junker R, Chung AY, Blüthgen N. 2007. Interaction between flowers, ants and pollinators: additional evidence for floral repellence against ants. Ecological Research 22: 665-670.

Karban R, Baldwin IT. 2007. Induced responses to herbivory. Chicago, University of Chicago Press.

Konstantinidis N, Duffy J, Bennington CC. 2010. Biological defense in Passiflora incarnata: evidence for a chemical defense against ant defenders. Florida Scientist 73: 1-9.

Leal IR, Fischer E, Kost C, Tabarelli M, Wirth R. 2006. Ant protection against herbivores and nectar thieves in Passiflora coccinea flowers. Ecoscience 13: 431-438.

Lenth RV. 2016. Least-Squares Means. R Package 'Ismeans'. Journal of Statistical Software 69: 33. doi: doi: 10.18637/jss. v069. i01

LeVan KE, Holway DA. 2015. Ant-aphid interactions increase ant floral visitation and reduce plant reproduction via decreased pollinator visitation. Ecology 96: 1620-1630.
Lortzing T, Calf OW, Boehlke M, et al. 2016. Extrafloral nectar secretion from wounds of Solanum dulcamara. Nature Plants 2: 1-6.

McCall AC, Irwin RE. 2006. Florivory: the intersection of pollination and herbivory. Ecology Letters 9: 1351-1365.

Mesquito-Neto JN, Paiva EAS, Galetto L, Schlindwein C. 2020. Nectar secretion of floral buds of Tococa guianensis mediates interactions with generalist ants that reduce florivory. Frontiers in Plant Science 11: 627. doi: 10.3389/fpls.2020.00627

Moreira X, Castagneyrol B, Abdala-Roberts L, Traveset A. 2019. A meta-analysis of herbivore effects on plant attractiveness to pollinators. Ecology 100: e02707. doi: 10.1002/ecy.2707

Ness JH. 2006. A mutualism's indirect costs: the most aggressive plant bodyguards also deter pollinators. Oikos 113: 506-514.

Pio-Corrêa M. 1978. Dicionário das plantas úteis do Brasil e das exóticas cultivadas. Rio de Janeiro, Ministério da Agricultura.

R Development Core Team. 2018. R: A language and environment for statistical computing. R Foundation for Statistical Computing, Vienna. https://www.r-project.org. 30 Jun. 2020.

Raine N, Willmer P, Stone G. 2002. Spatial structuring and floral avoidance behavior prevent ant-pollinator conflict in a Mexican ant acacia. Ecology 83: 3086-3096.

Ribeiro JELS, Hopkins MJG, Vicentini A, et al. 1999. Flora da Reserva Ducke. Guia de identificação das plantas vasculares de uma floresta de terra-firme na Amazônia Manaus, Central. Manaus, Instituto Nacional de Pesquisas da Amazônia - Inpa.

Rico-Gray V, Oliveira PS. 2007. Mutualism from antagonism: ants and flowers. In: Rico-Gray V, Oliveira PS. (eds.) The ecology and evolution of ant-plant interactions. Chicago, University of Chicago Press. p. 85-98.

Rodrigues DJ, Izzo TJ, Battirola LD. 2011. Descobrindo a Amazônia Meridional: Biodiversidade da Fazenda São Nicolau. Cuiabá, Pau e Prosa Comunicação.

Santos ATF, Leal LC. 2019. My plant, my rules: bodyguard ants of plants with extrafloral nectaries affect patterns of pollinator visits but not pollination success. Biological Journal of the Linnean Society 126: 158-167.

Stamp N. 2003. Out of the quagmire of plant defense hypotheses. The Quarterly Review of Biology 78: 23-55.

Storti EF. 2002. Biologia floral e sistema reprodutivo de Passiflora coccinea Aubl. em Manaus, AM. Acta Amazonica 32: 421-429.

Teixido AL, Barrio M, Valladares F. 2016. Size matters: understanding the conflict faced by large flowers in Mediterranean environments. The Botanical Review 82: 204-228.

Trager MD, Bhotika S, Hostetler JA, et al. 2010. Benefits for plants in antplant protective mutualisms: a meta-analysis. PLOS One 5: e14308. doi: 10.1371/journal.pone.0014308

Varassin IG, Trigo JR, Sazima M. 2001. The role of nectar production, flower pigments and odour in the pollination of four species of Passiflora (Passifloraceae) in south-eastern Brazil. Botanical Journal of the Linnean Society 136: 139-152.

Venables WN, Ripley BD. 2013. Modern Applied Statistics with S-Plus. Berlin, Springer.

Vicente RE, Izzo TJ. 2017. Defining habitat use by the parabiotic ants Camponotus femoratus (Fabricius, 1804) and Crematogaster levior (Longino, 2003). Sociobiology 64: 373-380

Villamil N, Boege K, Stone GN. 2019. Testing the Distraction Hypothesis: do extrafloral nectaries reduce ant-pollinator conflict? Journal of Ecology 107: 1377-1391.

Weber MG, Porturas LD, Keeler KH. 2015. World list of plants with extrafloral nectaries. http://www.extrafloralnectaries.org/. $31 \mathrm{Jul}$. 2020

Willmer PG. 2011. Pollination and floral ecology. Princeton, Princeton University Press.

Willmer PG, Nuttman CV, Raine NE, et al. 2009. Floral volatiles controlling ant behaviour. Functional Ecology 23: 888-900.

Wilmer PG, Stone GN. 1997. How aggressive ant-guards assist seed-set in Acacia flowers. Nature 388: 165-167.

Wirth RW, Leal IR. 2001. Does rainfall affect temporal variability of ant protection in Passiflora coccinea? Ecoscience 8: 450-453. 